\title{
Late-onset multiple acyl-CoA dehydrogenase deficiency with breast cancer
}

\author{
Keechilat Pavithran ${ }^{1 *}$ DD, Divya Pachat ${ }^{2}$ and Dehannathparambil Kottarathil Vijaykumar ${ }^{3}$
}

\begin{abstract}
Background: Multiple acyl-CoA dehydrogenase deficiency (MAAD) is a rare metabolic disorder resulting from an abnormality in fatty acid oxidation. There are three types of presentations: neonatal onset with or without congenital anomalies and the late-onset type. There is much clinical heterogeneity in the presentation of late-onset variants; hence, the diagnosis is often delayed or missed.

Case presentation: Here, we report the successful management of a 41-year-old female with late-onset MAAD due to mutation in the ETFDH gene who presented with carcinoma of the breast. Chemotherapy was challenging because there were no previous reports regarding the treatment of such cases.

Conclusion: The diagnosis was made based on metabolic workup and gene mutation analysis. Unplanned surgery and chemotherapy can be fatal in these patients due to metabolic complications. With proper precautions and monitoring, the patient tolerated surgery and chemotherapy without any complications.
\end{abstract}

Keywords: Multiple acyl-CoA dehydrogenase deficiency, MADD, Glutaric aciduria type II, Fatty acid metabolism

\section{Background}

Multiple acyl-CoA dehydrogenase deficiency (MADD, OMIM \#231680) glutaric acidemia type II is a rare metabolic disorder [1]. MAAD is an autosomal-recessive disorder of fatty acid oxidation resulting from defects in electron transfer flavoprotein (ETF) or electron transfer flavoprotein dehydrogenase $(E T F D H)$ [2]. There are three types of presentations: neonatal onset with or without congenital anomalies and the late-onset type [3]. MAAD may present as a severe neonatal-onset form with congenital anomalies (type I) or without congenital anomalies (type II). Type III is the most common presentation, and it can present from infancy to adulthood. The age of onset is highly variable. In an analysis of 350 individuals with late-onset MADD, the mean age at diagnosis was 17.6 years (range of 0.13 to 69 years) [3].
Clinical presentation is also very variable-from asymptomatic adults to fatal metabolic crisis during infancy. The most common symptoms are muscle weakness, exercise intolerance, and rhabdomyolysis [4]. Rarely, individuals with late-onset MAAD develop sensory neuropathy. One-third of patients develop acute metabolic decompensation. Diagnostic delays are common and often missed because of the highly variable clinical presentation. Early accurate diagnosis is important because late-onset MAAD is a treatable disorder, and a missed diagnosis can be fatal due to severe metabolic acidosis. Here, we report the successful management of breast cancer in a 41-year-old female who had late-onset MADD. The incidental occurrence of malignancy in a patient with MADD, which poses challenges in the management of cancer, has not been reported previously.

\footnotetext{
* Correspondence: drkpavithran@hotmail.com

${ }^{1}$ Department of Medical Oncology, Amrita Institute of Medical Science and

Research center, Amrita Vishwa Vidyapeetham, Kochi, Kerala, India

Full list of author information is available at the end of the article
}

(c) The Author(s). 2020 Open Access This article is licensed under a Creative Commons Attribution 4.0 International License, which permits use, sharing, adaptation, distribution and reproduction in any medium or format, as long as you give appropriate credit to the original author(s) and the source, provide a link to the Creative Commons licence, and indicate if changes were made. The images or other third party material in this article are included in the article's Creative Commons licence, unless indicated otherwise in a credit line to the material. If material is not included in the article's Creative Commons licence and your intended use is not permitted by statutory regulation or exceeds the permitted use, you will need to obtain permission directly from the copyright holder. To view a copy of this licence, visit http://creativecommons.org/licenses/by/4.0/. 


\section{Case presentation}

We report the case of a 41-year-old married female of South Indian origin, the third born to nonconsanguineous parents, with MADD who presented with carcinoma of the right breast. Her male sibling had been diagnosed with MADD in 2015 (at the age of 45 years) when he presented with acute hepatic encephalopathy and renal failure, requiring intensive care and ventilatory support. The prompt diagnosis of MADD by metabolic assay turned out to be life-saving for the sibling. In the wake of this genetic diagnosis, his siblings were also evaluated thoroughly. Our patient had a history of nonspecific symptoms such as tiredness and occasional vomiting from the age of 8 years. Laboratory investigations showed increased creatine phosphokinase (CPK) with mildly elevated liver enzymes. Similar to that of her brother, her tandem mass spectrometry (TMS) of blood showed a low free/acylcarnitine ratio and an acylcarnitine profile suggestive of
MADD, with elevated C6, C8, C10, C10:1, C12, and C14, C14:1 (Table 1). Gas chromatography-mass spectrometry (GC-MS) of urine showed a small peak of glutaric acid and 2-hydroxyglutaric acid with the presence of ethylmalonic acid and isobutyrylglycine and elevated hexanoylglycine, again indicating MADD. Mutational analysis of the family revealed both of these siblings to be homozygotes for the c.226G >A (p.A76T) variant of the $E T F D H$ gene.

She was started on oral riboflavin and carnitine supplementation. She was encouraged to reduce fat in her diet and simultaneously increase carbohydrate intake. She responded well to treatment, and within a few weeks, her biochemical parameters, including $\mathrm{CPK}$, liver function test (LFT) and carnitine/acylcarnitine profile, all reached baseline. From then onwards, she was regularly monitored, ensuring normal clinical and biochemical profiles to prevent an acute crisis similar to that in her brother.

Table 1 Serum acylcarnitine profile at diagnosis (TMS)

\begin{tabular}{|c|c|c|c|c|c|c|}
\hline & Acylcarnitines & Values ( $\mu \mathrm{mol} / \mathrm{L})$ & Cut-offs ${ }^{a}(\mu \mathrm{mol} / \mathrm{L})$ & Ratios & Values & Cut-offs ${ }^{\mathrm{a}}$ \\
\hline 1 & $C 2$ & 10.42 & 25.0 & $\mathrm{C} 3 / \mathrm{CO}$ & & 0.20 \\
\hline 2 & $C 3$ & 0.66 & $6.00^{\mathrm{a}}$ & $\mathrm{C} 3 / \mathrm{C} 2$ & & 0.20 \\
\hline 3 & $C 3 D C$ & 0.02 & $0.30^{\mathrm{a}}$ & $\mathrm{C} 3 / \mathrm{C} 16$ & & 3.50 \\
\hline 4 & C 4 & 0.39 & $1.30^{\mathrm{a}}$ & $\mathrm{C} 4 / \mathrm{C} 2$ & & 0.10 \\
\hline 5 & $\mathrm{C} 4-\mathrm{OH}$ & 0.01 & $0.65^{\mathrm{a}}$ & $\mathrm{C} 4 / \mathrm{C} 3$ & & 0.70 \\
\hline 6 & $C 4 \mathrm{DC}$ & 0.13 & 0.63 & & & \\
\hline 7 & C 5 & 0.47 & $0.70^{\mathrm{a}}$ & $\mathrm{C} 5 / \mathrm{C} 2$ & & 0.05 \\
\hline 8 & $\mathrm{C} 5-\mathrm{OH}$ & 0.12 & $0.90^{\mathrm{a}}$ & $\mathrm{C} 5-\mathrm{OH} / \mathrm{C2}$ & & 0.04 \\
\hline 9 & C $5: 1$ & 0.01 & $0.25^{\mathrm{a}}$ & C5:1/C2 & & 0.20 \\
\hline 10 & C 5 DC & 0.10 & $0.35^{\mathrm{a}}$ & $\mathrm{C} 5 \mathrm{DC} / \mathrm{C2}$ & & 0.02 \\
\hline 11 & C 6 & 0.75 & $0.45^{\mathrm{a}}$ & $\mathrm{C} 5 \mathrm{DC} / \mathrm{C} 12$ & & \\
\hline 12 & $\mathrm{C} 6 \mathrm{OH}$ & 0.13 & 0.35 & & & \\
\hline 13 & C 8 & 1.85 & $0.45^{\mathrm{a}}$ & $\mathrm{C} 8 / \mathrm{C} 2$ & 0.18 & 0.03 \\
\hline 14 & C 10 & 3.69 & $0.45^{\mathrm{a}}$ & $\mathrm{C} 10: 1 / \mathrm{C} 2$ & & \\
\hline 15 & C $10: 1$ & 0.26 & $0.30^{\mathrm{a}}$ & & & \\
\hline 16 & C $10: 2$ & 0.02 & $0.15^{\mathrm{a}}$ & & & \\
\hline 17 & C 12 & 2.84 & 0.50 & & & \\
\hline 18 & C 14 & 1.58 & $0.80^{\mathrm{a}}$ & $\mathrm{C} 14 / \mathrm{C} 2$ & 0.15 & 0.03 \\
\hline 19 & C $14: 1$ & 0.96 & $0.60^{\mathrm{a}}$ & C14:1/C16 & 0.38 & 0.30 \\
\hline 20 & C14:2 & 0.15 & 0.15 & & & \\
\hline 21 & C 16 & 2.24 & $7.50^{\mathrm{a}}$ & & & \\
\hline 22 & C 16-OH & 0.02 & $0.15^{\mathrm{a}}$ & $\mathrm{C} 16-\mathrm{OH} / \mathrm{C} 2$ & & 0.01 \\
\hline 23 & C 18 & 1.02 & $2.50^{\mathrm{a}}$ & C18:1/C2 & & 0.15 \\
\hline 24 & C 18-OH & 0.01 & $0.10^{\mathrm{a}}$ & & & \\
\hline 25 & C 18: 1 & 1.58 & $3.50^{\mathrm{a}}$ & $\mathrm{C} 18-\mathrm{OH} / \mathrm{C2}$ & & 0.10 \\
\hline \multirow[t]{2}{*}{26} & C 18: 1-OH & 0.02 & 0.16 & $\mathrm{C} 18: 1 \mathrm{OH} / \mathrm{C2}$ & & 0.01 \\
\hline & Total & 29.45 & & & & \\
\hline
\end{tabular}


In February 2019, she presented to the oncology outpatient department with a lump in the right breast. There was no family history of breast cancer. Systemic examination was normal. There was no hepatomegaly. She underwent a modified radical mastectomy in March 2019. During the intra- and postoperative period, special care was taken to prevent hypoglycemia and acidosis with close monitoring of blood sugar and arterial blood gas (ABG) levels. Glucose infusion was given to keep her blood sugar levels at $>100 \mathrm{mg} / \mathrm{dl}$. She recovered without any complications. Histopathological analysis revealed infiltrating mammary carcinoma, grade 3; pTNM-pT1c N1 M0. Immunohistochemical analysis showed estrogen receptor (ER) moderate positivity in $50-60 \%$ of cells, progesterone receptor (PR) moderate positivity in 50$60 \%$ of cells, Her2 negativity and Ki67 positivity in $40 \%$ of cells. $B R C A$ mutation analysis showed two heterozygous "variants of uncertain significance" (VUS): one "VUS" was detected in exon 19 of the BRCA2 gene, and another "VUS" was detected in exon 4 of the PALB2 gene. She had 4 cycles of adjuvant chemotherapy with docetaxel and cyclophosphamide and completed radiotherapy in July 2019. Anthracycline-containing drugs were avoided, as individuals with late-onset MAAD are prone to develop cardiomyopathy.

The problems that we expected in addition to the metabolic complications were mainly chemotherapyinduced vomiting and neutropenia-related sepsis. Therefore, she was instructed to take more fluid and eat a carbohydrate-rich diet. However, her blood sugar was always in the low-to-normal range $(70-90 \mathrm{mg} / \mathrm{dl}$ range). Therefore, she was given $1 \mathrm{~L}$ of $10 \%$ dextrose before chemotherapy infusions, and her blood sugar, carnitine (Table 2), and ABG levels were monitored. Additionally, a strong antiemetic regimen (aprepitant, palonosetron, dexamethasone, and olanzapine) was given to prevent chemotherapy-induced nausea and vomiting. To prevent neutropenia, prophylactic granulocyte colony-stimulating factor (G-CSF) was given. Riboflavin and carnitine were continued. With this regimen, she tolerated the chemotherapy well (with only grade 2 nausea). No special care was needed during radiation therapy, as it was directed to the chest wall, and systemic side effects were not expected. Currently, she is on tamoxifen and was doing well during the last 14 months of follow-up.

\section{Discussion}

Inborn errors of metabolism (IEM) associated with malignancies are sometimes defined as a probable causative factor or a coincidence. The following are ways in which IEM can predispose patients to malignancies: (i) mitochondrial dysfunction (e.g., myoclonic epilepsy associated with ragged red fibers (MERRF) - multiple familial lipomas); (ii) the accumulation of toxins (e.g., Gaucher's disease type 1-multiple myeloma and leukemia; hemochromatosis-hepatocellular carcinoma); (iii) the generation of oncometabolites (e.g., fumarate hydratase mutation-hereditary leiomyomatosis and renal cell cancer syndrome; succinate dehydrogenase deficiency-pulmonary chondromas, hereditary paragangliomas, gastric stromal tumors, renal tumours, and pheochromocytomas); and (iv) metabolic rewiring (e.g., glycogen storage disease-hepatocellular carcinoma) [5]. There are reports of glutaric acidemia type I-associated brain tumors, such as medulloblastoma and glioblastoma [6]. However, there are no reports of malignancies occurring in patients with glutaric acidemia type II or MAAD.

The diagnosis of MADD in our patient was confirmed by the presence of elevated acylcarnitine levels in the blood, along with increased excretion of multiple organic acids in urine, as reported previously [4]. The vast majority of the mutations (93\%) occur in the ETFDH gene [3]. The c.250G $>\mathrm{A}$ mutation is the most common mutation $(28.1 \%)$ in reported cases, followed by c.770A $>\mathrm{G}$ (12.9\%), c.1227A $>\mathrm{C}(8.9 \%)$, and c.1130 $\mathrm{T}>\mathrm{C}(6.3 \%)$ [7]. Most of these cases are reported from Southeast Asia. There are only a few reports from India $[8,9]$. Genetic studies were not done in these cases. Our patient had the c.226G>A (p.A76T) variant of the ETFDH gene. This appears to be a novel variant. Previously, a mutation in the same nucleotide (c.226) and codon (p.76) of the ETFDH gene was reported, but the amino acid substitution was different (Ala $\rightarrow$ Lys vs $\mathrm{Ala} \rightarrow \mathrm{Ser}$ and $\mathrm{Ala} \rightarrow \mathrm{Thr}$ ) [10]. The mainstay of management includes the limitation of protein and fat in the diet and the avoidance of prolonged fasting and high-dose riboflavin, carnitine, and coenzyme $\mathrm{Q}_{10}$ supplements. As in our patient, the vast majority of late-onset MADD patients respond very well to riboflavin. Perioperative management includes avoiding prolonged fasting, hypoglycemia, and acidosis [4]. Supportive care during chemotherapy in such cases is not known, but we could manage our patient's

Table 2 Carnitine values before, during, and after chemotherapy

\begin{tabular}{llllll}
\hline & At the time of diagnosis & Pre chemo values & Post chemo values & Current values & Normal range \\
\hline Total carnitine & $56.14 \mu \mathrm{mol} / \mathrm{L}$ & $50.56 \mu \mathrm{mol} / \mathrm{L}$ & $55.28 \mu \mathrm{mol} / \mathrm{L}$ & $53.46 \mu \mathrm{mol} / \mathrm{L}$ & $20-87.7 \mu \mathrm{mol} / \mathrm{L}$ \\
Free carnitine & $26.69 \mu \mathrm{mol} / \mathrm{L}$ & $42.46 \mu \mathrm{mol} / \mathrm{L}$ & $35.23 \mu \mathrm{mol} / \mathrm{L}$ & $43.22 \mu \mathrm{mol} / \mathrm{L}$ & $24.7-66.6 \mu \mathrm{mol} / \mathrm{L}$ \\
Acylcarnitine & $29.45 \mu \mathrm{mol} / \mathrm{L}$ & $8.1 \mu \mathrm{mol} / \mathrm{L}$ & $20.05 \mu \mathrm{mol} / \mathrm{L}$ & $10.24 \mu \mathrm{mol} / \mathrm{L}$ \\
Free/acyl ratio & 0.91 & 5.24 & 1.76 & 4.22 & $>2.0$ \\
\hline
\end{tabular}


condition by applying the same principles. Emergency treatment includes hospitalization with intravenous fluid containing $10 \%$ dextrose and bicarbonate therapy depending on the metabolic status. The prognosis of patients with late-onset MADD is generally good. However, 5\% mortality has been reported from metabolic decompensations [3].

\section{Conclusion}

This report describes the successful management (surgery, chemotherapy, and radiotherapy) of a patient with late-onset MAAD who developed breast cancer. The occurrence of malignancy in a patient with MADD has not been reported previously, and our patient had a novelvariant ETFDH gene mutation. Although MAAD is rare, high awareness of this disease is needed among clinicians because late-onset presentation is common, and it is a treatable disorder.

\section{Abbreviations}

ABG: Arterial blood gas; BRCA: BReast CAncer gene; CPK: Creatine phosphokinase; ETFDH: Electron transfer flavoprotein-ubiquinone oxidoreductase; GC-MS: Gas chromatography-mass spectrometry; G-CSF: Granulocyte colony-stimulating factor; LFT: Liver function test; MAAD: Multiple acyl-CoA dehydrogenase deficiency; OMIM: Online Mendelian Inheritance in Man; PALB2: Partner And Localizer of BRCA2; TMS: Tandem mass spectrometry; VUS: Variants of unknown significance

\section{Acknowledgements}

Dr Anil B. Jalan of Navi Mumbai Institute of Research in Mental and Neurological handicap (NIRMAN) for doing the metabolic workup.

\section{Authors' contributions}

DP analyzed and interpreted the patient data regarding the metabolic disorder, and oncological data was collected and analyzed by KP and DKV. All authors contributed equally in writing the manuscript. All authors read and approved the final manuscript.

\section{Funding}

No funding was received for this case report

\section{Availability of data and materials}

Data can be found in the archives of the Amrita Institute of Medical Sciences and Research Centre.

Ethics approval and consent to participate

Not applicable.

\section{Consent for publication}

Written informed consent was obtained from the patient.

\section{Competing interests}

The authors declare that they have no competing interests.

\section{Author details}

'Department of Medical Oncology, Amrita Institute of Medical Science and Research center, Amrita Vishwa Vidyapeetham, Kochi, Kerala, India. ${ }^{2}$ Department of Medical Genetics, Aster MIMS (Malabar Institute of Medical Sciences), Calicut, India. ${ }^{3}$ Amrita Centre for Breast Diseases, Amrita Institute of Medical Science and Research Center, Amrita Vishwa Vidyapeetham, Kochi, Kerala, India.
Received: 27 September 2020 Accepted: 2 December 2020

Published online: 12 December 2020

References

1. Przyrembel H, Wendel U, Becker K, Bremer HJ, Bruinvis L, Ketting D et al (1976) Glutaric aciduria type II: report on a previously undescribed metabolic disorder. Clin Chim Acta. 66:227-239

2. Frerman FE, Goodman SI (2001) Defects of electron transfer flavoprotein and electron transfer flavoprotein-ubiquinone oxidoreductase; glutaric aciduria type II. In: Scriver CR, Beauder AL, Sly WS, Valle D (eds) The metabolic and molecular bases of inherited diseases, 8th edn. McGraw-Hill, New York, pp 2357-2365

3. Grünert SC (2014) Clinical and genetical heterogeneity of late-onset multiple acyl-coenzyme A dehydrogenase deficiency. Orphanet J Rare Dis. 9:1-8. https://doi.org/10.1186/s13023-014-0117-5

4. Prasun P. Multiple acyl-CoA dehydrogenase deficiency. In: Adam MP, Ardinger $\mathrm{HH}$, Pagon RA, et al.. GeneReviews ${ }^{\circledast}$. Seattle: University of Washington, Seattle; 2020.

5. Erez A, DeBerardinis RJ (2015) Metabolic dysregulation in monogenic disorders and cancer - finding method in madness. Nat Rev Cancer. 15:440448

6. Serrano Russi A, Donoghue S, Boneh A, Manara R, Burlina AB, Burlina AP (2018) Malignant brain tumors in patients with glutaric aciduria type I. Mol Genet Metab. 125:276-280

7. Chen W, Zhang Y, Ni Y, Cai S, Zheng X, Mastaglia FL et al (2019) Late-onset riboflavin-responsive multiple acyl-CoA dehydrogenase deficiency (MADD): Case reports and epidemiology of ETFDH gene mutations. BMC Neurol. 19: 1-7. https://doi.org/10.1186/s12883-019-1562-5

8. Pooja M, Subasree R, Sumanth S, Kumar MV, Gayathri N, Rashmi S (2017) Multiple acyl CoA dehydrogenase deficiency: uncommon yet treatable disorder. Neurol India. 65:177-178. https://doi.org/10.4103/0028-3886.198186

9. Chandra SR, Christopher R, Narayanappa G, Ramanujam NC, Katragadda P, Huddar A et al (2018) Lipid storage myopathy with ketonuria: a case of fatty acid oxidation-related myopathy and encephalopathy due to multiple acylCoA dehydrogenase deficiency. J Pediatr Neurosci. 13:362

10. Xi J, Wen B, Lin J, Zhu W, Luo S, Zhao C et al (2014) Clinical features and ETFDH mutation spectrum in a cohort of 90 chinese patients with lateonset multiple acyl-CoA dehydrogenase deficiency. J Inherit Metab Dis. 37: 399-404. https://doi.org/10.1007/s10545-013-9671-6

\section{Publisher's Note}

Springer Nature remains neutral with regard to jurisdictional claims in published maps and institutional affiliations.

\section{Submit your manuscript to a SpringerOpen ${ }^{\circ}$ journal and benefit from:}

- Convenient online submission

- Rigorous peer review

- Open access: articles freely available online

High visibility within the field

- Retaining the copyright to your article

Submit your next manuscript at $>$ springeropen.com 